\title{
Bond Strength Performance of Resin Core Material with Glass Fiber Post: An In Vitro Study
}

\author{
Authors
Deepak Jaiswal ${ }^{1}$, Manjula Das ${ }^{2}$, Silpi Jalan ${ }^{3}$, Syeda Shamima Nastaran Quazi ${ }^{4}$, Swarga Jyoti Das ${ }^{5}$ \\ ${ }^{1}$ Regional Dental College, Guwahati-781032, Assam, India \\ Email:deep88735@gmail.com \\ ${ }^{2}$ Reader and Head of Prosthodontics, Regional Dental College, Guwahati-781032, Assam, India \\ Email:drmanjuladas@gmail.com \\ ${ }^{3}$ Lecturer, Department of Prosthodontics, Regional Dental College, Guwahati-781032, Assam, India \\ Email:drsilpijahan@gmail.com \\ ${ }^{4}$ PRCA, Department of Prosthodontics, Regional Dental College, Guwahati-781032, Assam, India \\ Email: quazishamima786@gmail.com \\ ${ }^{5}$ Department of Periodontics and Implantology, Regional Dental College, Guwahati-781032, Assam, India \\ Corresponding Author \\ Dr Swarga Jyoti Das
}

Professor and Head, Department of Periodontics and Implantology, Regional Dental College, Guwahati781032, Assam, India

Phone no. 0091-361-2463050, Fax No. 0091-361-2529877

Email:swargajyoti_das2@rediffmail.com

\begin{abstract}
Tooth-coloured fiber posts allow better reproduction of the underlying natural tooth shade, thus results in a more aesthetic restoration. The clinical success of a post and core restoration depends on the composite resin selected and the quality of the post and core interface, where materials of different compositions are in intimate retentive contact. The aim of this study was to measure the bond strength between Fiber reinforced composite-Glass fiber (FRC) post and three different types of dual cure composite core materials, namely Luxacore Z, Compcore AF and Paracore. A total of 60 test samples, 20 in each dual cure resin core material were prepared to assess the tensile bond strength between the core material and glass fiber post. The samples were then positioned on the testing jig and the retention tests were performed with universal testing machine. Failure load was registered in MPa (megapascals).Each failed specimen was observed with an optical microscope (Dinolite, ANMO Electronics Corporation) at x 20 magnifications, in order to classify the type of failure. Out of the three tested dual cure core materials, the Paracore revealed the highest tensile bond strength with glass fiber post followed by Luxacore $Z$ and Compcore AF ( $F$ value of $8.75, p<0.0005$ ) and all three dual cure resin core groups showed predominantly adhesive fractures between post and core.

Keywords: Fiber reinforced composite-Glass post, dual cure, composite, core material, tensile strength.
\end{abstract}




\section{Introduction}

The restoration of endodontically treated teeth with a significant loss of coronal tooth structure may require the placement of a post to ensure ample retention of core foundation. The use of prefabricated posts and resin restorative materials to fabricate post and core systems was introduced in the 1960s, subsequently, that leads to the development of a biocompatible endodontic post that fulfils the functional and aesthetic demands. Glass fiber post is one of such kinds. The primary advantage of this post is its modulus of elasticity that closely approximates to that of dentin, thus flexion of post mimics the tooth flexion. So, the post acts as a shock absorber, transmitting only a fraction of the stresses placed upon the tooth to the dentinal walls. In addition, glass fiber posts have a high aesthetic potential. In addition, glass fiber posts are reported to be readily retrievable after failure, whereas the metallic and ceramic post systems are non-retrievable (Cormier et al., 2001) ${ }^{1}$.

To build up endodontically treated teeth, various composite resins are available. However, self cure, hybrid and flow able composites have been employed in recent both in vivo and in vitro (Alirenza and Anne, 2009) ${ }^{2}$. No universal post and core system is accepted for all tooth or clinical situations. Hence it is the clinician's role to make an appropriate decision, after weighing the merits and demerits of the factors influencing post and core selection. The retention of the composite core to the prefabricated post is influenced by several factors including the surface structure and the design of the post head, the post material, and the resin composite core materials (Ioli-Ioanna et al., 2006; Passos et al., 20011) ${ }^{3,4}$. Core build up material with greater retention are more resistant to dislodgement due to lateral occlusal stresses. The interaction between composite resins and fiber post is critical for the success of restorations placed over these materials (Roxana et al., 1996) ${ }^{5}$. Use of dual cure composite core materials has increased to a large extent. The inherent retention and stability of the core built from various dual cure composite core materials with respect to the post are crucial for long term success of restoration. Hence, this study was planned to determine the bond strength between Fiber reinforced composite-Glass fiber (FRC) post and three different types of dual cure composite core materials and also to evaluate the modes of failure between post and core.

\section{Materials and Methods}

In this vitro study, 60 prefabricated glass fiber posts, namely Rely X fiber post (3M ESPE, Germany) were taken and divided into 3 groups based on the Bonding agents:

Group I: Luxacore Z (DMG Chemisch Pharma zeutische, Hamburg, Germany)

Group II: Compcore AF(Premier Dental Products, PA, U.S.A)

Group III: Paracore (Coltene Whaledent, USA)

The bonding agents were applied on the post surface with brush. The core build up materials were manipulated and cured according to manufacturer's instructions. A core of $4 \mathrm{~mm}$ height was prepared around the Fiber reinforced composite-Glass fiber (FRC) post by using transparent, cylindrical prefabricated plastic mould with a measurement of $10 \mathrm{~mm}$ and $4 \mathrm{~mm}$ inner diameter and height, respectively. The dimensions were measured using a vernier caliper. During the core build-up procedure, each post was positioned upright on a glass slab and secured with a drop of sticky wax. Then, a cylindrical plastic mould was placed around the post and adjusted so that placement of the post is exactly in the centre. The specimens were stored in distilled water at $37^{\circ} \mathrm{C}$ for 24 hours to simulate conditions in the oral cavity. The samples were then positioned on the testing jig and the retention tests were performed with universal testing machine (Model No.8801J4051, Instron-Dynamic UTM). Each specimen was loaded at a cross-head speed of $0.5 \mathrm{~mm} / \mathrm{min}$ until failure occurred at post -core interface or within post or within core. Failure load was registered in MPa (megapascals).Each failed specimen was observed under an optical 
microscope (Dinolite, ANMO Electronics Corporation) at $\mathrm{x} 20$ magnifications in order to classify the type of failure. The kind of failures considered were adhesive between post and core, Cohesive within post, or cohesive within core with load post-core retention and was determined by recording the tensile force required to dislodge the post from the core material.

The data were analyzed statistically using SAS System (Local X64_7PRO). One way ANOVA was performed as the parametric test to compare the three groups, being $\mathrm{p}$ value $<0.05$ was considered as significant of variance.

\section{Results}

In this study, the tensile bond strength of three different dual cure composite core materials, namely Luxacore $\mathrm{Z}$ (group I), Comp core AF (group II) and Paracore (group III) with Fiber reinforced composite-Glass fiber (FRC) post. Out of the three tested dual cure core materials, the Paracore revealed the highest tensile bond strength with FRC post followed by Luxacore $\mathrm{Z}$ and Compcore AF (F value of 8.75, $\mathrm{p}<0.0005$ ) (Table 1).

The failure mode was compared and found to be predominantly adhesive between post and core (Table 2).

Table 1: Retention values of three dual cure resin materials in $\mathrm{MPa}$

\begin{tabular}{|l|c|}
\hline Groups & Retention values(MPa) \\
\hline Group I(n=20) & 15.62 \\
& $(14.95-16.28)$ \\
\hline Group II(n=20) & 15.46 \\
Group III $(\mathrm{n}=20)$ & $(14.77-16.13)$ \\
\hline
\end{tabular}

Table 2. Failure mode of three dual cure resin materials bonded to FRC post

\begin{tabular}{|c|c|c|c|}
\hline \multirow{2}{*}{ Groups } & \multicolumn{3}{|c|}{ Failure } \\
\cline { 2 - 4 } & Adhesive & Cohesive & Post \\
\hline Group I (n=20) & 20 & 0 & 0 \\
\hline Group II (n=20) & 19 & 1 & 0 \\
\hline Group III (n=20) & 10 & 0 & 1 \\
\hline
\end{tabular}

\section{Discussion}

Since the introduction of prefabricated glass fiber posts, a sustained effort has been made to improve the bonding potential of current adhesive systems to the post and core restoration. Although dentinal/cemental interface is a key factor for long-term clinical success of a luted post to root dentin, the glass fiber post/core interface also requires attention, as several studies pointed out this interface as the weak link in the adhesion process (Mylswamy et al., 2011) ${ }^{6}$.

Various studies reported that dual cure composites are preferable to light-curing composites for core build-up on a fiber post considering their higher bond strengths with the glass fiber posts (Ziad Salameha et al., 2006; Kerstin et al., 2008) ${ }^{7.8}$.In contrast, Zahra Khamverdi et al., (2011) concluded that microhybrid and flowable composites provide more acceptable bond strength in comparison to packable materials ${ }^{9}$. Our findings support the observation of Ziad Salameha et al., (2006) ${ }^{7}$, who reported that placement of bonding agent between the glass fiber post and dual cure resin core increases the bond strength. Besides, the retention value obtained in the dual cure resin core group was found to be higher than that of light cure resin core, probably due to its easier handling characteristics, excellent adaptability at the post surface and its low viscosity. In addition, its higher filler content absorbs stresses resulting in higher bond strength.

The present study is an attempt to compare the retention of Luxacore, Compcore AF and Paracore to the prefabricated FRC. Every effort was made to select the specimens of comparable physical characteristics and standardize the procedures accurately. The tapered FRC of diameter $1.60 \mathrm{~mm}$ and length $20 \mathrm{~mm}$ was selected to simulate the length and post space of the anterior teeth. The prefabricated matrix used for making the specimens was standardized to the selected diameters, which correspond to the mesio-distal widths of anterior teeth measured at the level of the cemento-enamal junction after crown preparation. Besides, all the specimens used in the 
study were prepared using the same plastic mould, to avoid the influence of post and core of variable dimensions on retention.

In the present study, the mean retention value ingroup I was $15.62 \mathrm{MPa}$, while in group II and III were 15.46 and $17.37 \mathrm{MPa}$, respectively. Thus, group III shows the highest retention values followed by group I and II. The differences among the groups were very highly significant $(\mathrm{p}<0.0005)$. However, Tukey's post hoc multiple comparison test showed no significant difference between group I and group II ( $p=0.723$ ), whereas significant differences were observed between group I and group III ( $p=0.002)$, and group II and III $(p=0.001)$. Thus, a conclusion may be drawn from the present study that, the retentive strength of Paracore (group III) to the glass fiber post is significantly higher than that of the Luxacore $\mathrm{Z}$ (group I)and Compcore AF (group II). This supports the finding of Peterson et al., $(2005)^{10}$.

In the present study, we have compared 3dual cure composite core build up materials namely, Luxacore, Compcore AF and Paracore with some structural and chemical differences. One of the composite resin ingredients which affects the mechanical properties, is the size, type and content of the filler. Luxacore $\mathrm{Z}$ has $71 \%$ filler content by weight, while Compcore AF and Paracore have $77 \%$ and $68 \%$ by weight, respectively. However, percentage of fillers in the composite resins is not the only factor that affects the tensile strength, there are other factors that affect the mechanical properties of composite resins, including degree of conversion, fillermatrix bond in the oral environment, type of polymerization, polymerization shrinkage, reinforcement with fibers, etc.,. Paracore is reinforced with glass fibers, which affects the fracture process results in interrupting crack growth progression and thus enhances the fracture toughness of the fiber-reinforced composite material. Thus, the differences in retention value among these three dual cure composite core materials may be due to the difference in their handling characteristics, compositions (such as matrix type, filler type, filler load) and properties (such as polymerization ability, flexural strength, hardness, fiber reinforcement). These differences may also have an effect on their adhesion to tooth substrate.

The present study also investigated the mode of failures. All three dual cure resin core groups showed predominantly of adhesive fractures. In group I, all specimens showed adhesive fracture between posts and cores. In both group II and group III 19, out of 20 specimens showed adhesive failure. The findings of the present study are consistent with the observation of Sadek et al. (2007) ${ }^{11}$, and Zahra Khamverdi et al., (2011) .

The limitations of the present study are that the tests do not simulate the clinical situations. They are far harsher than the actual forces seen in the oral cavity. In the oral cavity, the tensile force is important but there are many masticatory forces. Situations in which only pure tensile stresses are being applied are not very common. In addition, the post and core is covered by a crown that tends to distribute the masticatory stresses more evenly to the complex of root and post and core. Therefore, this study gives us a relative order of the property of the material being tested. However, further long term studies are necessary to precisely correlate the implications of this study to clinical success.

\section{Conclusion}

The bond strength between fiber post and core material is one of important criterion for selection of a core material. In the present study, Paracore showed the greatest retention value with glass fiber post, and the highest tensile bond strength in comparison to Compcore AF and Luxacore $\mathrm{Z}$ core material. All three dual cure resin core groups showed predominantly adhesive fractures between post and core.

\section{Reference}

1. Cormier C J, Burns D R, Moon P. In vitro comparison of the fracture resistance and failure mode of fiber, ceramic, and 
conventional post systems at various stages of restoration. J Prostho, 2001:10: 26-36.DOI: $10.1111 /$ j.1532849X.2001.00026.x

2. Alireza S, Anne P. Durability of the bond between resin composite cores and prefabricated posts. ActaOdontolScandi, 2009:67: 271-276. doi.org/10.1080/00016350902938571

3. Ioli-IoannaArtopoulou, Kathy L. O'Keefe, John M. Powers. Effect of Core Diameter and Surface Treatment on the Retention of Resin Composite Cores to Prefabricated Endodontic Posts , J Prostho,2006 :15:172179.DOI: $10.1111 / \mathrm{j} .1532-$ 849X.2006.00097.

4. Passos S P, Santos M J, El-Mowafy O, Rizkalla AS,Santos GC. Diametral tensile strength of composite core material with cured and uncured fiber posts .General Dentistry,2011:125-8; quiz 129-30.

5. Roxana Stegaroiu, Hiroyuki Yamada, Haruka Kusakari and Osamu Miyakawa. Retention and failure mode after cyclic loading in two post and core systems ,J Prosthet Dent 1996; 75: 50611.DOI: doi.org/10.1016/S0022-

3913(96)90454-0

6. Mylswamy Sumitha, Rajkumar Kothandaraman, Mahalaxmi Sekar. Evaluation of post-surface conditioning to improve interfacial adhesion in post-core restorations ,Journal of Conservative Dentistry, 2011:14: 28-31

7. Salameh Z, Papacchini F, Ounsi HF, Goracci C, Tashkandi E, Ferrari $M$. Adhesion Between Prefabricated Fiberreinforced Posts and Different Composite Resin Cores: A Microtensile Bond Strength Evaluation, J Adhes Dent, 2006:8: 113-117.

8. Bitter K, Neumann K, Kielbassa AM. Effects of Pretreatment and Thermocycling on Bond Strength of Resin Core Materials to Various Fiber-reinforced Composite Posts, J Adhes Dent, 2008:10: 481-489.

9. Khamverdi Z, Kasraei S, Azarsina M, Gheysari F. Microtensile bond strength of quartz fiber posts to different composites. Braz Oral Res.2011;25:295301.

10. Petersen R.C. Discontinuous fiberreinforced composites above critical length .J Dent Res.2005; 84:365-70. doi.org/10.1177/154405910508400414.

11. Sadek F T, Monticelli, F, Goracci, C, Tay F R, Cardoso P E C, Ferrari M.. Bond strength performance of different resin composites used as core materials around fiberposts, Dental Materials 23 ,2007: 9599. DOI: $10.1016 / j$.dental.2005.12.005. 